\title{
The Establishment of the Proportion of Stress Levels and Its Association with the Demographic Factors among Individuals That Participated in the Taxpayers' Appreciation Week 2018, Kampala, Uganda
}

\author{
Nabunya Mariah Peggy', Nwanna Uchechukwu Kevin ${ }^{2 *}$, Rebecca Suubi ${ }^{3}$, \\ Awunor Nyemike Simeon4, Ilori Oluwole ${ }^{4}$, Aremu Abdulmujeeb Babatunde ${ }^{4}$, Fred Kasirye ${ }^{5}$ \\ ${ }^{1}$ Public Health Department, Victoria University, Kampala, Uganda \\ ${ }^{2}$ Faculty of Health Sciences, Victoria University, Kampala, Uganda \\ ${ }^{3}$ Nutrition and Dietetics Department, Victoria University, Kampala Uganda \\ ${ }^{4}$ Nursing/Midwifery Department, Victoria University, Kampala, Uganda \\ ${ }^{5}$ Faculty of Humanities and Social Sciences, Victoria University, Kampala, Uganda \\ Email: *uchenwanna1@gmail.com, *uche4score@yahoo.com
}

How to cite this paper: Peggy, N. M., Kevin, N. U., Suubi, R., Simeon, A. N., Oluwole, I., Babatunde, A. A., \& Kasirye, F. (2020). The Establishment of the Proportion of Stress Levels and Its Association with the Demographic Factors among Individuals That Participated in the Taxpayers' Appreciation Week 2018, Kampala, Uganda. Psychology, 11, 1854-1861. https://doi.org/10.4236/psych.2020.1112117

Received: September 27, 2019

Accepted: December 14, 2020

Published: December 17, 2020

Copyright $\odot 2020$ by author(s) and Scientific Research Publishing Inc. This work is licensed under the Creative Commons Attribution International License (CC BY 4.0).

http://creativecommons.org/licenses/by/4.0/ (c) (i) Open Access

\begin{abstract}
Introduction: Stress can affect people of all ages, genders and circumstances and can lead to both physical and psychological health issues. Stress is the emotional and physical strain caused by our response to pressure from the outside world. Chronic stress affects your capability to concentrate, act professionally and efficiently and makes you more accident-prone. Objective: The purpose of this study was to determine the association between the various levels of stress with the demographic factors among individuals that participated in Uganda's tax payer's appreciation week in the year 2018 held in Kampala. Methodology: This study utilised a cross-sectional study design that incorporated quantitative research methods and convenience sampling technique was used in this study to gather the information from the 390 respondents. Data were analysed using SPSS version 20; univariate and bivariate analysis was done to measure the association between stress and the participant's demographic characteristics. Results: This research study revealed that none of the variables (age, gender, marital status and education level) was statistically significant with stress levels, hence no association was established. Conclusion: The results from this research indicated that there was no significant association between the demographic factors of the respondents and stress levels. Furthermore, the proportion of stress levels showed that
\end{abstract}


majority of the respondents recruited for this research study were moderately stressed (54.2\%) and the minority had low stress (18.9\%). Recommendations: Individuals should maintain a healthy lifestyle both physically, emotionally and socially to keep their stress levels low or moderate.

\section{Keywords}

Stress Levels, Taxpayers, Physical Health Issues

\section{Introduction}

Stress can affect people of all ages, genders and circumstances and can lead to both physical and psychological health issues. By definition, stress is any uncomfortable emotional experience accompanied by predictable biochemical, physiological and behavioural changes, American Psychological Association (2018). Stress is the emotional and physical strain caused by our response to pressure from the outside world, Sharma \& Kaur (2011). A study carried out on social workers by Kabunga \& Kihoro (2014) in Northern Ugandan in 2014, this study established that majority of the respondents, ninety-one (91\%) percent had high-stress levels. Some of the major factors that contributed to stress included but not limited to finances, work demand, safety concerns, family and violence from the rebels.

According to Wiegner et al. (2015), the prevalence of stress in a working-age population seeking primary health care for whatever reason, is unknown. In 2009, a study on stress was carried out in a Swedish population aged 16 - 84, using the General Health Questionnaire (GHQ 12). The study reported thirteen (13\%) percent of the population to have stress and three (3\%) percent were reported to have severe stress.

In another study by Wiegner et al. (2015), fifty-nine (59\%) percent of the study respondents showed stress levels 2 or 3 (237 women and 108 men). Women indicated higher levels of stress than men; sixty-four (64\%) percent women and thirty-six (36\%) percent men. Out of these, forty-one (41\%) percent scored perceived stress level 1 (women 37\%, men 49\%), Twenty-six (26\%) percent scored stress level 2 (women 26\%, men 26\%), and thirty-three (33\%) percent scored stress level 3 (women 36\%, men 26\%). Mean age was 42 years (range 18 - 65). There were differences noticed between the stress level groups regarding gender and marital status where the percentage of women was higher and the percentage of singles increased with increasing level of stress. Two-thirds of the research respondents conveying stress levels 2 - 3 indicated a high degree of fatigue, and approximately half of them indicated Exhaustion Disorder (ED). Among highly stressed patients (level 3), thirty-three (33\%) percent reported symptoms indicative of possible depression and sixty-four (64\%) percent possible anxiety.

Education also contributes to increased stress levels. Stress is increasingly becoming common among college students Katie \& Megan (2011). According to a 
study carried out by Sharma \& Kaur (2011), there is increasing appreciation of stressors witnessed in Medical and nursing training College students, particularly freshmen, who seem to be prone to stress due to the transitional nature of college life. More than a quarter of all college students report that they are unable to manage their stress. Since the majority of college students do not visit clinics where stress assessments are carried out, methods of identifying the students who may be experiencing adverse consequences from stress continue to be indefinable.

\section{Methodology}

\subsection{Study Design}

This study utilised a cross-sectional study design that incorporated a quantitative research method of inquiry because quantitative methods provide hard data needed to achieve the required objectives.

\subsection{Study Setting and Location}

The data collection was conducted at Kololo Airstrip, Kampala, Uganda.

\subsubsection{Study Population}

The study involved both male and female individuals who attended the Taxpayers Appreciation week celebrations.

\subsubsection{Sample Size}

The sample size was 390 and this was determined by the number of individual respondents that enrolled for the research study while at the tent that was set up during the Taxpayers Appreciation week celebrations 2018.

\subsubsection{Sampling Strategies and Procedures}

A convenience sampling technique was used in this study to gather information from the respondents. The respondents in this study were gotten based on convenience. The research team set up a tent for different tests to be done and upon arrival; individuals were told about the on-going study and were requested to participate. Only those who consented took part in this study.

\subsubsection{Inclusion Criteria}

This study included a cross-section of individuals that agreed to participate in the study that was carried out during the Taxpayers Appreciation week celebrations in 2018.

\subsubsection{Exclusion Criteria}

This study excluded all children and infants that attended the Taxpayers Appreciation week celebrations that took place in 2018.

\subsubsection{Data Collection Methods}

A structured questionnaire was used to obtain data from the individuals using only quantitative methodology. 


\subsection{Measurement of Variables}

\subsubsection{Independent Variables}

Demographic factors: Attributes such as age, gender, marital status and education level were controlled by using essential questions related to each attribute.

\subsubsection{Dependent Variable}

Stress Levels: Attributes such as low stress, moderate stress and high stress were controlled by using essential questions related to each attribute.

\subsection{Data Analysis}

Organizing data was done through a constant comparative data method of analysis as a method used to construct categories or themes by continuous comparison of bits of data with each other using SPSS version 20. Uni-variate and Bi-variate analyses were done to analyse the data.

\subsection{Ethical Considerations}

An approval letter to carry out the study was obtained from the Victoria University Uganda research and ethical committee (VU-FHS-REC-0025). Guidelines were adopted and emphasized in the questionnaire i.e. the purpose of the study was explained to participants utilizing information sheet. The participants were assured of strict confidentiality of any information they provided.

\section{Results}

\subsection{Uni-Variate Analysis}

From the assessment of the demographic factors, it is seen from the table that for the variable of age majority of the respondents were in the age group of 21-25 years with a percentage of $24.1 \%$ and the minority were in the age group of 15 years and below with a percentage of $0.8 \%$. Also, for the aspect of gender, the majority of the respondents were males (51.2\%). Furthermore, for the variable of marital status, majority of the respondents were single with a percentage of $53.7 \%$ and the minority was widowed with a percentage of $2.3 \%$, also for education level, the highest level of education that majority of the respondents attained as at that time was the secondary level of education (38.1\%) and the minority had not attained any education at that time (2.3\%) (Table 1 ).

Results for stress levels showed that majority of the respondents were moderately stressed with a frequency of (217) and the minority had low stress having a frequency of (76) (Table 2).

The figure below shows that $55.6 \%$ of the respondents were moderately stressed being the majority, $24.9 \%$ were highly stressed; while $19.5 \%$ of the respondents had low-stress levels making them the minority (Figure 1).

\subsection{Bi-Variate Analysis}

From the bivariate analysis; under the category of low stress revealed that res- 
pondents within the age groups of 41 - 45 years and 46 - 50 years of age were more likely to experience low stress as compared to other age groups, for moderate stress, respondents who fell within the age group of 15 years and below were more likely to experience moderate stress as compared to other age groups and for the category of high stress, respondents who were 51 years and above were more likely to be highly stressed than those in other age groups and this

Table 1. Demographic factors of the respondents.

\begin{tabular}{|c|c|c|c|}
\hline No & Variable & Frequency $(n=390)$ & Percentage (\%) \\
\hline \multirow[t]{10}{*}{1.} & Age (years) & & \\
\hline & 15 and below & 3 & 0.8 \\
\hline & $16-20$ & 29 & 7.4 \\
\hline & $21-25$ & 94 & 24.1 \\
\hline & $26-30$ & 85 & 21.8 \\
\hline & $31-35$ & 57 & 14.6 \\
\hline & $36-40$ & 44 & 11.3 \\
\hline & $41-45$ & 28 & 7.2 \\
\hline & $46-50$ & 21 & 5.4 \\
\hline & $51+$ & 29 & 7.4 \\
\hline \multirow[t]{3}{*}{2.} & Gender & & \\
\hline & Male & 200 & 51.2 \\
\hline & Female & 190 & 48.6 \\
\hline \multirow[t]{5}{*}{3.} & Marital Status & & \\
\hline & Married & 159 & 40.7 \\
\hline & Single & 210 & 53.7 \\
\hline & Divorced & 12 & 3.1 \\
\hline & Widowed & 9 & 2.3 \\
\hline \multirow[t]{6}{*}{4.} & Education Level & & \\
\hline & No education & 9 & 2.3 \\
\hline & Primary & 64 & 16.4 \\
\hline & Secondary & 149 & 38.1 \\
\hline & Tertiary institution & 64 & 16.4 \\
\hline & University & 104 & 26.6 \\
\hline
\end{tabular}

Table 2. Frequency of stress levels among respondents.

\begin{tabular}{ccc}
\hline & Stress Levels & Frequency $(\mathrm{n}=390)$ \\
\hline 1. & Low & 76 \\
2. & Moderate & 217 \\
3. & High & 97 \\
\hline
\end{tabular}




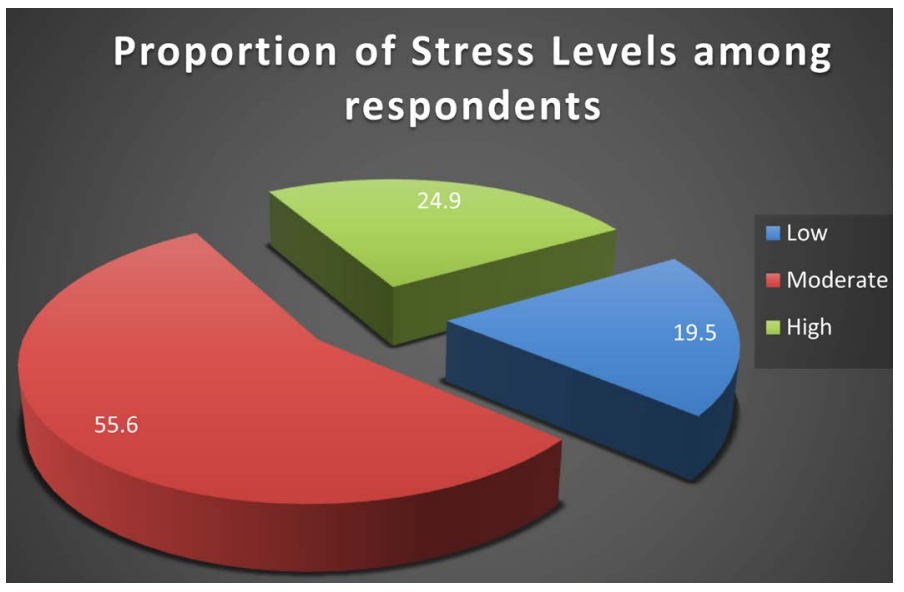

Figure 1. Stress levels among the respondents.

was not statistically significant $\left(\mathrm{X}^{2}=12.489 ; P\right.$-value $\left.=0.710\right)$. Additionally, for the variable of gender under the category of low stress, male respondents were less likely to experience low stress as compared to the female respondents, under the category of moderate stress, female respondents were less likely to be moderately stressed than their male counterparts and for the category of high stress, female respondents were less likely to be highly stressed than their male counterparts and this was not statistically significant $\left(\mathrm{X}^{2}=0.787 ; P\right.$-value $\left.=0.675\right)$.

For the variable of marital status under the category of low stress, married respondents were more likely to experience low stress as compared to the respondents of another marital status, under the category of moderate stress, respondents who were widowed were more likely to be moderately stressed than the respondents of another marital status while under the category of high stress, respondents who were divorced were more likely to have high stress than respondents of other marital status and this was not statistically significant $\left(\mathrm{X}^{2}=\right.$ 5.076; $P$-value $=0.534)$. Furthermore, for the variable of education level under the category of low stress, respondents with no education level were more likely to experience low stress than those who attained an education level, while under the category of moderate stress, respondents with primary level education were more likely to be moderately stressed than those who attained other education levels and under the category of high stress, respondents who attained tertiary institution education were more likely to be highly stressed than those who attained other education levels and this was not statistically significant $\left(\mathrm{X}^{2}=7.618\right.$; $P$-value $=0.472)($ Table 3$)$.

\section{Discussion}

This research study revealed that none of the variables (age, gender, marital status and education level) was statistically significant with stress levels, hence no association was established. This result was in line with the results from Rhode \& Okwo (2012), which stated that there was no significant relationship between demographic factors and stress levels. However, results from Rexroth 
Table 3. Demographic factors of the respondents associated with stress levels.

\begin{tabular}{|c|c|c|c|c|c|c|}
\hline \multirow[b]{2}{*}{ No } & \multirow[b]{2}{*}{ Variable } & \multicolumn{3}{|c|}{ Stress Levels } & \multirow[b]{2}{*}{$\begin{array}{c}\text { Chi-square } \\
\qquad\left(x^{2}\right)\end{array}$} & \multirow[b]{2}{*}{$p$-value } \\
\hline & & $\begin{array}{c}\text { Low } \\
\text { Freq. (\%) }\end{array}$ & $\begin{array}{l}\text { Moderate } \\
\text { Freq. (\%) }\end{array}$ & $\begin{array}{c}\text { High } \\
\text { Freq. (\%) }\end{array}$ & & \\
\hline \multirow[t]{10}{*}{1.} & Age (years) & & & & 12.489 & 0.710 \\
\hline & 15 and below & $0(0.0 \%)$ & $3(100 \%)$ & $3(0.0 \%)$ & & \\
\hline & $16-20$ & $3(10.3 \%)$ & $21(72.4 \%)$ & $5(17.2 \%)$ & & \\
\hline & $21-25$ & $18(19.1 \%)$ & $51(54.3 \%)$ & $25(26.6 \%)$ & & \\
\hline & $26-30$ & $18(21.2 \%)$ & $49(57.6 \%)$ & $18(21.2 \%)$ & & \\
\hline & $31-35$ & $13(22.8 \%)$ & $31(54.4 \%)$ & $13(22.8 \%)$ & & \\
\hline & $36-40$ & $9(20.5 \%)$ & $21(47.7 \%)$ & $14(31.8 \%)$ & & \\
\hline & $41-45$ & $8(28.6 \%)$ & $14(50.0 \%)$ & $6(21.4 \%)$ & & \\
\hline & $46-50$ & $6(28.6 \%)$ & $11(52.4 \%)$ & $4(19.0 \%)$ & & \\
\hline & $51+$ & $4(13.8 \%)$ & $15(51.7 \%)$ & $10(34.5 \%)$ & & \\
\hline \multirow[t]{3}{*}{2.} & Gender & & & & 0.787 & 0.675 \\
\hline & Male & $37(18.5 \%)$ & $113(56.5 \%)$ & $50(25.0 \%)$ & & \\
\hline & Female & $42(22.1 \%)$ & $103(54.2 \%)$ & $45(23.7 \%)$ & & \\
\hline \multirow[t]{5}{*}{3.} & Marital Status & & & & 5.076 & 0.534 \\
\hline & Married & $39(24.5 \%)$ & $83(52.2 \%)$ & $37(23.3 \%)$ & & \\
\hline & Single & $37(17.6 \%)$ & $120(57.1 \%)$ & $53(25.2 \%)$ & & \\
\hline & Divorced & $2(16.7 \%)$ & $6(50.0 \%)$ & $4(33.3 \%)$ & & \\
\hline & Widowed & $1(11.1 \%)$ & $7(77.8 \%)$ & $1(11.1 \%)$ & & \\
\hline \multirow[t]{6}{*}{4.} & Education Level & & & & 7.618 & 0.472 \\
\hline & No education & $4(44.4 \%)$ & $3(33.3 \%)$ & $2(22.2 \%)$ & & \\
\hline & Primary & $14(21.9 \%)$ & $38(59.4 \%)$ & $12(18.8 \%)$ & & \\
\hline & Secondary & $31(20.8 \%)$ & $85(57.0 \%)$ & $33(22.1 \%)$ & & \\
\hline & Tertiary institution & $9(14.1 \%)$ & $36(56.3 \%)$ & $19(29.7 \%)$ & & \\
\hline & University & $21(20.2 \%)$ & $54(51.9 \%)$ & $29(27.9 \%)$ & & \\
\hline
\end{tabular}

et al. (2013) stated that age influences stress which was one of the variables under demographic factors.

\section{Conclusion}

The results from this research indicated that there was no significant association between the demographic factors of the respondents and stress levels. Furthermore, the proportion of stress levels showed that majority of the respondents recruited for this research study were moderately stressed (54.2\%) and the minority had low stress (18.9\%).

\section{Recommendation}

This research study from its findings, recommends that individuals should 
maintain a healthy lifestyle both physically, emotionally and socially to keep their stress levels extremely low.

\section{Limitation of the Study}

In carrying out this research study a limitation was encountered concerning the language barrier, but this was overcome by having various interpreters of the different dialects.

\section{Conflicts of Interest}

The authors declare no conflicts of interest regarding the publication of this paper.

\section{References}

American Psychological Association (2018). Understanding Chronic Stress. https://www.apa.org/helpcenter/understanding-chronic-stress.aspx

Kabunga, A., \& Kihoro, M. (2014). Work Stress and Coping Strategies among Social Workers: A Case of Northern Uganda.

Katie, G., \& Megan, A. (2011). Prevalence of Stress References on College Freshmen.

Rexroth, D. F., Tennstedt, S. L., Jones, R. N., Guey, L. T., Rebok, G. W., Marsiske, M. M., Xu, Y., \& Unverzagt, F. W. (2013). Relationship of Demographic and Health Factors to Cognition in Older Adults in the ACTIVE Study. Journal of Aging and Health, 25, 128S-146S. https://doi.org/10.1177/0898264313498415

Rhode, F., \& Okwo, F. (2012). Influence of Demographic Factors on Stress Perceptions of Teachers of Public Secondary Schools in Cameroon.

Sharma, N., \& Kaur, A. (2011). Factors Associated with Stress among Nursing Students. Nursing and Midwifery Research Journal, 7, 12-21. https://doi.org/10.33698/NRF0119

Wiegner, L., Hange, D., Björkelund, C., \& Ahlborg, G. (2015). Prevalence of Perceived Stress and Associations to Symptoms of Exhaustion, Depression and Anxiety in a Working Age Population Seeking Primary Care-An Observational Study. BMC Family Practice, 16, Article No. 38. https://doi.org/10.1186/s12875-015-0252-7 